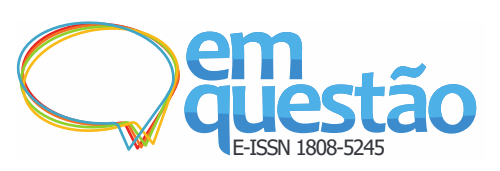

\title{
Mulheres com deficiência na docência brasileira
}

\author{
Daniela Priscila de Oliveira Veronezi \\ Mestre; Universidade Federal de Goiás, Goiânia, GO, Brasil; \\ danielaveronezi@gmail.com; ORCID: https://orcid.org/0000-0003-0148-5145 \\ Geisa Müller de Campos Ribeiro \\ Mestre; Universidade Federal de Goiás, Goiânia, GO, Brasil; \\ geisamuller@ufg.br; ORCID: https://orcid.org/0000-0001-5778-1248 \\ Suely Henrique de Aquino Gomes \\ Doutora; Universidade Federal de Goiás, Goiânia, GO, Brasil; \\ suelyhenriquegomes@gmail.com; ORCID: https://orcid.org/0000-0002-5711-483X
}

\begin{abstract}
Resumo: O objetivo desta investigação é discutir a representatividade das mulheres com deficiência na docência do ensino superior brasileiro. Parte-se do entendimento de que os sujeitos da pesquisa apresentam dois marcadores de silenciamento e de exclusão: ser mulher e com deficiência. Quanto aos aspectos metodológicos, a pesquisa classifica-se como quantitativa. Pautou-se na análise secundária dos dados do Instituto Nacional de Estudos e Pesquisas Educacionais Anísio Teixeira (INEP), de 2010 e 2018, bem como dos dados gerais do Instituto Brasileiro de Geografia e Estatística (IBGE). Com esta investigação, observou-se que os docentes com deficiência representam somente $1 \%$ dos que compõem o ensino superior brasileiro, sendo as mulheres a minoria se comparadas à quantidade de homens, embora os gráficos evidenciem um aumento quantitativo na representatividade feminina ao longo dos anos.
\end{abstract}

Palavras-chave: Ciência e gênero; Ensino superior; Exclusão; Ciência e minoria.

\section{Introdução}

A população brasileira é composta, em sua maioria, pelo sexo feminino. Segundo dados do IBGE Educa (2018), as mulheres representam 51,7\% do total e os homens, 48,3\%. Em relação à deficiência, os dados da Cartilha do Censo 2010 - Pessoas com Deficiência, da Secretaria de Direitos Humanos da Presidência da República (SDH/PR) (2012), evidenciam que 45.606.048 de 
brasileiros, ou seja, 23,9\% da população do país, possui ao menos um tipo de deficiência, seja ela física ou intelectual.

Além desses dados, o Censo 2010 também mensurou o quantitativo de brasileiros com deficiência por sexo, detectando que 25.800 .681 de pessoas com deficiência, no Brasil, são mulheres, enquanto 19.805 .367 são homens (SECRETARIA..., 2012). Apesar desses números expressivos tanto em relação ao montante de mulheres no país quanto, mais especificamente, em relação às que têm algum tipo de deficiência, nota-se que as mulheres com deficiência pouco ingressam na carreira de docência do ensino superior brasileiro.

É notório que tanto as mulheres quanto outras pessoas com deficiência constituem grupos subalternizados frente à soberania da masculinidade e dos sujeitos ditos "perfeitos" ou "normais". Além disso, a ciência moderna e os pressupostos fundadores da produção científica, como construtos simbólicos do dispositivo de verdade, fundam e fixam um sujeito universal de produção de conhecimento, deixando de lado aqueles que escapam do seu modelo de referência.

Nesse sentido, ser mulher e ainda com deficiência significa agregar dois estigmas num único sujeito, aprofundando ainda mais preconceitos arraigados na sociedade e, em consonância, a exclusão torna-se marca deveras profunda no cotidiano dessas pessoas que convivem dentro de uma cultura marcadamente androcêntrica e que cultua a perfeição. Isso porque o "corpo científico" como construto simbólico é normatizado, regulado e enquadrado em padrões culturais que tentam invisibilizar a multiplicidade e a diversidade.

Se ser mulher e ocupar um lugar de distinção na ciência já é difícil, como seria se, além do gênero, outra etiqueta qualificadora (deficiência) fosse agregada? Com base nesse panorama, a inquietação que motiva as pesquisadoras a empreender a investigação proposta neste artigo está em discutir qual a representatividade da mulher com deficiência na docência do ensino superior no Brasil? Sabe-se que são tardias as leis de inclusão neste país, todavia, elas têm possibilitado que se amplie a participação de pessoas com deficiência no ensino 
superior. Ainda assim, muitas dificuldades se encontram nas sólidas barreiras de acesso à escola, ao ensino superior e, consequentemente, à carreira docente.

A partir de uma breve pesquisa inicial sobre a participação da mulher com deficiência na docência ${ }^{1}$ na Biblioteca Digital Brasileira de Teses e Dissertações e no Google Acadêmico, observou-se que muitas pesquisas estão direcionadas à acessibilidade, à inclusão social e ao desenvolvimento de instrumentações pedagógicas focadas no acesso e na permanência do discente, mas não do docente. Nesse sentido, a falta de produção na temática deste artigo apresenta indícios de uma naturalização da ausência de professoras(es) com deficiência no ensino superior brasileiro.

Mesmo silenciadas e com pouca visibilidade, sabe-se que as mulheres com deficiência podem contribuir para o avanço do campo científico no Brasil. Portanto, tensionar esse lugar é deslegitimar formas de poder, de exclusão, de dominação, de violência e de silenciamentos. Segundo Farias (2011), apesar da força constrangedora que desde cedo perturba e esgota o desenvolvimento humano integral da pessoa com deficiência, há muitas mulheres que manifestam sua força interna para romper com as dificuldades do dia a dia.

A fim de buscar respostas à inquietação que norteia esta investigação, como método de pesquisa, a abordagem classifica-se em quantitativa. Já em relação aos objetivos, define-se como exploratória. Para complementar as discussões, realiza-se uma análise dos dados secundários do Instituto Nacional de Estudos e Pesquisas Educacionais Anísio Teixeira (INEP), de 2010 e 2018, bem como dos dados gerais do IBGE. A primeira parte do trabalho busca refletir sobre desigualdade de gênero e mulher com deficiência, isto é, as condições de vulnerabilidade que os marcadores "ser mulher" e "ser deficiente" expressam.

Em um segundo momento, promove-se a discussão sobre a carreira científica e a invisibilização de sujeitos decorrente da visão reducionista que atravessa suas trajetórias e do próprio contexto científico que é historicamente considerado um domínio reservado aos homens brancos. A ciência, enquanto agenciamento específico, regula corpos, invisibiliza, fixa e silencia a mulher com deficiência e a coloca em outros lugares. Na terceira parte, realiza-se uma 
análise dos dados do INEP com base no construto teórico desta investigação.

Nessa perspectiva, acredita-se que tensionar os estigmas sociais que tradicionalmente excluem as mulheres com deficiência da docência do ensino superior brasileiro e apresentar algumas reflexões acerca dessa temática são formas de contribuir para romper com o silêncio e, assim, fortalecer a produção científica de mulheres como um meio de mitigar os estereótipos de gênero e corroborar para estimular o protagonismo de outras mulheres.

\section{Desigualdade de gênero e mulher com deficiência}

As compreensões sobre deficiência perpassam as dinâmicas culturais e criam encadeamentos que marcam trajetórias e modos de organização social dos espaços e das relações. Nesse sentido, a deficiência pode ser compreendida como "[...] produto do entrelace de diversas produções discursivas, que se interrelacionam com a linguagem, a ideologia e o imaginário social, influenciando condutas e práticas frente a ela" (GOMES et al., 2019, p. 1). Pode-se dizer que se trata de uma narrativa fabricada do corpo, mas que não se encerra no corpo, abarcando suas relações com o ambiente e a produção de estrutura, instituições, subjetividades e práticas culturais (MELLO; NUERNBERG, 2012).

Um dos modelos que tem permeado diversas discussões sobre a deficiência é o biomédico, pautado no conhecimento científico e nos padrões de normalidade. Segundo esse modelo, a deficiência está relacionada às lesões e a impedimentos físicos, sensoriais e intelectuais. Contudo, esse modelo, a partir de uma perspectiva reducionista, invisibiliza os demais elementos constituintes da deficiência e produz "[...] opressão e vulnerabilidade, tornando precárias as condições de existência das pessoas" (GOMES et al., 2019, p. 10). É nesse viés que o padrão normativo de corpo é desenhado, tornando-se ininteligíveis as corporeidades que escapam desse modelo.

Portanto, a partir das diversas críticas que perpassam o modelo médico, emerge o modelo social da deficiência, para o qual a responsabilidade pelos processos de opressão é vista como da sociedade. Segundo Mello e Nuernberg: 
O modelo social da deficiência, em oposição ao paradigma biomédico, não se foca nas limitações funcionais oriundas de deficiência nem propõe a ideia tão comumente aceita da necessidade de reparação/reabilitação do corpo deficiente, mas sim a concebe como o resultado das interações pessoais, ambientais e sociais da pessoa com seu entorno. Nesse sentido, as experiências de opressão vivenciadas pelas pessoas com deficiência não estão na lesão corporal, mas na estrutura social incapaz de responder à diversidade, à variação corporal humana. (MELLO; NUERNBERG, 2012, p. 638).

Esse modelo levou as pessoas com deficiência à esfera dos direitos humanos, não as reduzindo a objetos de intervenção clínica, de reabilitação ou tão somente de assistencialismo. Também oportunizou discussões relacionadas à experiência da deficiência e à reformulação de marcos legais e políticos. A ideia foi alargar a compreensão da deficiência como uma questão multidisciplinar e não exclusiva do discurso médico sobre a lesão.

A interface da deficiência com o feminismo surge entre os anos de 1990 e 2000 a partir das discussões pós-estruturalistas sobre o papel da experiência e a subjetividade do corpo. "Especialmente em relação às discussões teóricas sobre os modelos da deficiência e à deficiência como uma condição de vulnerabilidade para a violência de gênero" (MELLO; NUERNBERG, 2012, p. 639). Para Diniz (2007, p. 26), “[...] a analogia entre a opressão do corpo deficiente e o sexismo era um dos pilares que sustentavam a tese dos deficientes como minoria social". Foram as discussões feministas que trouxeram à tona temas esquecidos na agenda de discussões do modelo social. A mesma autora ressalta:

Falaram do cuidado, da dor, da lesão, da dependência e da interdependência como temas centrais à vida do deficiente. Elas levantaram a bandeira da subjetividade do corpo lesado, discutiram o significado da transcendência do corpo por meio da experiência da dor, e assim forçaram uma discussão não apenas sobre a deficiência, mas sobre o que significava viver em um corpo doente ou lesado. (DINIZ, 2007, p. 27).

Além dos aspectos apresentados da experiência da opressão pelo corpo deficiente, as discussões feministas mostraram a convergência de outras variáveis de desigualdade, como raça, gênero, orientação sexual ou idade. É a partir do termo "natural" (identidades de homem e de mulher, entre biologia e 
comportamento), alocado como elemento que fixa sujeitos, que os debates se tensionam.

Butler (2003) diz que algumas teorias feministas, principalmente aquelas classificadas como de primeira e de segunda ondas, na busca por uma representatividade social, unificaram os discursos e os sujeitos do feminismo, cristalizando a identidade de "mulher" a partir de um modelo universal. Essa mulher é inclusive de corpo "perfeito", com um modelo específico. O próprio conceito de gênero produz uma identidade que passa a ser reconhecida como algo ontológico e metafísico capaz de reduzir as experiências subjetivas.

Por essa razão, a autora explica que gênero é uma agremiação que extrapola a categoria mulher e precisa superar essa produção binária que vai sempre diferenciar sexo de gênero. Em razão disso, no interior do próprio discurso feminista, a categoria "mulher" é afirmada por meio da representação política - termo operacional para estender visibilidade e legitimidade às mulheres como sujeitos políticos. "O sujeito é uma questão crucial para a política e particularmente para a política feminista, pois os sujeitos jurídicos são invariavelmente produzidos por via de práticas de exclusão que não aparecem, uma vez estabelecida a estrutura jurídica da política" (BUTLER, 2003, p. 190).

Isso denota que a construção política do sujeito é vinculada a objetivos de legitimação e de exclusão. Em uma sociedade na qual as pessoas são percebidas como seres humanos adequados, quando articulam uma coerência entre sexo, gênero e desejo, essas pessoas são colocadas no lugar de abjeto, ou seja, no que não é humano (BUTLER, 2003). É nesse contexto que um conjunto de pessoas abjetas vão sendo empurradas à margem dessa produção identitária, pois não se enquadram nas exigências normativas dessa categoria, dentre elas também se encontram as mulheres com deficiência.

Pode-se dizer que o contexto apresenta dois marcadores de silenciamento e de exclusão: ser mulher e com deficiência. Essas são duas condições vulnerabilizantes marcadas por experiências de subordinação, discriminação e desigualdade, somadas às diversas formas de violência. Uma dupla desvantagem que se torna ainda mais complexa ao se incorporar as categorias de raça/etnia, 
classe etc. No Brasil, ainda é possível visualizar as desigualdades e o silenciamento de muitas vozes. Corpos anônimos que são removidos de qualquer possibilidade ou capacidade de pensar e agir por si mesmos.

Essa é a experiência vivenciada por muitas mulheres com deficiência, caracterizadas como incapazes e postas em uma visão estigmatizante, pautada em valores e crenças que as posicionam como frágeis, vulneráveis e incapazes (de amar, sentir desejo, ter relações sexuais etc.). Essas exclusões reduzem suas chances de produção e de participação econômica e social da vida pública, fortalecendo a violência e o controle de seus corpos, relegando-as a uma posição subalternizada. A vida privada é o que lhes resta e a gestão de sua vida fica restrita, muitas vezes, à dependência e à superproteção familiar.

\section{Carreira científica e inviabilização de sujeitos}

A trajetória escolar e acadêmica de diversas mulheres com deficiência normalmente é marcada por uma série de obstáculos que impedem o acesso ao conhecimento formal. Como diz Farias (2017, p. 99), “A ideia de incapacidade de uma pessoa com deficiência é tão fortemente disseminada, que as expectativas de sucesso escolar por parte de pais e educadores/as diminuem consideravelmente quando se trata de estudantes nessa condição". Infelizmente, como consequência da visão reducionista que atravessa suas trajetórias, muitas não chegam ao ensino superior e muito menos concluem a pós-graduação, o que efetivamente dificulta a inserção na docência e na carreira científica.

Apesar das políticas públicas que asseguram alguns direitos da pessoa com deficiência, aspectos culturais e sociais ainda causam um descompasso em sua efetivação. Dentre eles, há que se dizer que os próprios princípios norteadores da Ciência Moderna durante muito tempo inviabilizaram ou dificultaram, sobremaneira, o acesso das mulheres com deficiência em diversas carreiras profissionais, inclusive a científica. Algumas pesquisas evidenciam que o conhecimento científico tem sido historicamente considerado um domínio reservado aos homens brancos (BANDEIRA, 2008). 
Pode-se dizer que há uma tradição cultural do fazer científico que sempre esteve associada ao masculino, a exemplo de alguns princípios norteadores da Ciência Moderna que, segundo Silva (2008, p. 135), “[...] balizaram a construção do conhecimento científico, abstraindo, declaradamente, toda possibilidade de considerar as mulheres como sujeitos de conhecimento e do conhecimento". Além disso, as estruturas sociais, o desenvolvimento econômico do país, o sistema educativo e a ausência de sistemas que viabilizem a vida profissional e familiar da mulher são elementos que dificultam sua inserção no contexto acadêmico.

Algumas formulações teóricas apresentam pressupostos que nortearam a produção do conhecimento, como: as condições de neutralidade com linguagem androcêntrica, o universalismo, o caráter progressista da racionalidade científica e a objetividade da ciência. Esses aspectos só reafirmam a figura de um sujeito universal. A objetividade e a neutralidade, nesse contexto, garantem a veracidade do conhecimento livre de vieses ideológicos e voluntaristas do sujeito produtor do conhecimento e instauram padrões de normatividade científica que deixam de lado aqueles que escapam desse modelo de referência (RAGO, 1998).

Para Silva e Ribeiro (2014, p. 452), "Na lógica das oposições binárias, que estruturam o pensamento moderno, o homem é a referência e a mulher é apresentada como o 'outro', o oposto do homem”. Nesse sentido, observa-se que a ciência não é neutra, ao contrário, constitui-se com base em fundamentos prédeterminados que posicionam ao centro as ideologias que perpassam esses ideais e, na periferia, as que não coadunam com esse padrão estabelecido.

No sistema periférico da ciência se encontram as mulheres, em especial nas consideradas "ciências superiores", a saber, as Naturais e as Exatas, devido ao rigor que apresentam segundo os padrões convencionados por esse movimento dominante da objetividade masculina. De acordo com Silva (2008, p. 135), "A universalidade científica traz o homem como representante da humanidade, considerando a mulher como uma variação humana, inferior e incapaz de ocupar esse lugar, devendo ser representada por este homem”. 
Se é um desafio para as mulheres se sobressair no campo científico, tendo em vista todo esse processo sócio-histórico de exclusão arraigado nos movimentos hegemônicos, ao se agregar à feminilidade um outro estigma periférico - a deficiência - a invisibilidade se aprofunda. Isso porque os sujeitos com deficiência travam lutas constantes para participarem do convívio social e apenas na contemporaneidade, mesmo que por obrigatoriedade legal, estão passando, pouco a pouco, a ocupar espaços, ainda que timidamente, nos diversos campos da sociedade.

Em relação às pessoas com deficiência, Piovesan (2013) delineia quatro fases vivenciadas por esses sujeitos no transcorrer da história. Na primeira, a intolerância, a deficiência representa a impureza e o castigo divino; na segunda, a invisibilidade, tanto a deficiência relativa quanto a absoluta são tidas como algo natural; na terceira, o assistencialismo, a deficiência é concebida como uma doença a ser curada, sendo o foco centrado no sujeito, portador da enfermidade; e na quarta, a inclusão, foca-se na relação entre a pessoa com deficiência e o meio no qual ela está inserida, bem como na necessidade de eliminar as barreiras existentes na sociedade que impossibilitam o pleno exercício de direitos. Dessa forma,

\begin{abstract}
Conceitua-se a inclusão social como um processo pelo qual a sociedade se adapta para poder incluir, em seus sistemas sociais gerais, pessoas com deficiência (além de outras) e, simultaneamente, estas se preparam para assumir seus papéis na sociedade. A inclusão social constitui, então, um processo bilateral no qual as pessoas, ainda excluídas, e a sociedade buscam, em parceria, equacionar problemas, decidir sobre soluções e efetivar a equiparação de oportunidades para todos. (SASSAKI, $1997^{2}$, p. 3 apud SASSAKI, 2010, p. 39).
\end{abstract}

Essa perspectiva conceitual vem ao encontro do pensamento de Barboza e Almeida Junior quando esses afirmam que, embora não antagonize com a integração, a inclusão "[...] dela se distingue por chamar a sociedade à ação, isto é, por exigir que a sociedade se adapte para acolher as pessoas com deficiência" (BARBOZA; ALMEIDA JUNIOR, 2017, p. 21), e não o contrário. A inclusão 
“[...] repousa em princípios até então considerados incomuns, tais como: a aceitação das diferenças individuais, a valorização de cada pessoa, a convivência dentro da diversidade humana, a aprendizagem através da cooperação" (SASSAKI, 2010, p. 40)

Para Mantoan (2017, p. 39), “a inclusão assegura o direito à diferença na igualdade de direitos".

Nesse sentido, cabe salientar que apenas na década de 1980 emergiram, com maior pujança, os movimentos sociais em prol da inclusão das pessoas com deficiência, atrelados a novos patamares mundiais de discussões acerca do tema. Essas perspectivas internacionais referentes à deficiência e à consequente influência nos movimentos sociais empreendidos no país repercutiram diretamente no texto da Constituição Federal de 1988, amplificando a aquisição de direitos dessa parcela da população. Em 1991, foi instituída a Lei n. 8.213, que "dispõe sobre os Planos de Benefícios da Previdência Social e dá outras providências" (BRASIL, 1991, p. 1), a qual, em seu artigo 93, disciplina sobre cotas para pessoas com deficiência nos seguintes termos:

Art. 93. A empresa com 100 (cem) ou mais empregados está obrigada a preencher de $2 \%$ (dois por cento) a $5 \%$ (cinco por cento) dos seus cargos com beneficiários reabilitados ou pessoas portadoras de deficiência, habilitadas, na seguinte proporção: I - até 200 empregados - 2\%; II - de 201 a 500 - 3\%; III - de 501 a 1.000 4\%; IV - de 1.001 em diante - 5\%. (BRASIL, 1991, p. 45).

Em relação aos concursos públicos, no âmbito das instituições de regime jurídico de direito público federais, há de se considerar a Lei n. 8.112, de 1990, que "Dispõe sobre o regime jurídico dos servidores públicos civis da União, das autarquias e das fundações públicas federais" (BRASIL, 1990, p. 1). Essa lei assegura às pessoas com deficiência "[...] o direito de se inscrever em concurso público para provimento de cargo cujas atribuições sejam compatíveis com a deficiência de que são portadoras; para tais pessoas serão reservadas até $20 \%$ (vinte por cento) das vagas oferecidas no concurso" (BRASIL, 1990, p. 2).

$\mathrm{O}$ arcabouço legislativo brasileiro acerca do tema fortaleceu-se com a Convenção Internacional sobre os Direitos das Pessoas com Deficiência e seu Protocolo Facultativo, admitida em 2006 pela Organização das Nações Unidas 
(ONU) e aprovada no Brasil em 2008, por meio do Decreto Legislativo n. 186 (BRASIL, 2008), com prerrogativa de emenda constitucional, sendo sancionada em 2009. Essa Convenção é considerada o grande marco da conquista dos direitos desses sujeitos e resultou na instituição da Lei Brasileira de Inclusão da Pessoa com Deficiência de n. 13.146 (BRASIL, 2015), conhecida como Estatuto da Pessoa com Deficiência, que delineia as diretrizes estratégicas que passaram a vigorar na Constituição Federal, a fim de concretizar os direitos desses sujeitos.

Com isso, ainda que impulsionadas por exigência legal, as pessoas com deficiência, antes apartadas do âmbito corporativo, passaram a se fazer presentes nas organizações nas últimas décadas. Dados da Secretaria Especial de Previdência e Trabalho ${ }^{3}$, do Ministério da Economia (2018), apontam que, após a intensificação das inspeções nas empresas, com o intuito de fiscalizar o cumprimento da Lei n. 8.213, em 2018, 46,9 mil pessoas com deficiência acessaram o mercado de trabalho. Embora aquém dos percentuais almejados, esses números são os maiores desde 2003, quando se iniciou a mensuração. Em comparação com 2017, as admissões foram majoradas em 20,6\%.

No entanto, será que na docência do ensino superior brasileiro há uma participação efetiva das pessoas com deficiência? Se os dados da Cartilha do Censo 2010 - Pessoas com Deficiência apontam que 23,9\% da população conta com algum tipo de deficiência e que há um predomínio das mulheres nessa condição (SECRETARIA..., 2012), também há um número maior de mulheres com deficiência na docência do ensino superior que o de homens? A legislação vigente, que estabelece percentuais mínimos de pessoas com deficiência nas organizações, consegue alcançar a docência do ensino superior brasileiro? Entre as mulheres, essa invisibilidade se agrava? Tais indagações margeiam a questãoproblema proposta por esta investigação, que se concentra em responder "qual a representatividade da mulher com deficiência na docência do ensino superior no Brasil?".

Para Silva (2008, p. 136), “[...] a ciência foi e é uma das instituições que mais tem se posicionado quanto às escolhas do que conhecer, para que conhecer, 
quem pode conhecer, bem como, para quem conhecer, uma vez que sempre esteve a serviço de grandes organizações ligadas ao capital". Nesse sentido, nas ciências, "[...] as mulheres como sujeitos individuais e coletivos e como sujeitos do conhecimento compartilham das mesmas exclusões e incertezas relativas a outros grupos sociais [...]" (BANDEIRA, 2008, p. 211). "Vale destacar que a teoria feminista, ao incorporar as alteridades, não se restringiu com exclusividade às mulheres, mas também absorveu outros sujeitos omitidos pelas grandes discursividades iluministas" (BANDEIRA, 2008, p. 221).

Essa crítica feminista à ciência possibilita tensionamentos em favor da participação de outros grupos subalternizados e periféricos frente à hegemonia científica. Os sujeitos com deficiência, por sua vez, estão, pouco a pouco, emergindo no convívio social, tanto no âmbito educacional quanto no corporativo, ainda que de forma incipiente. De todo modo, ascender ao mundo do trabalho não significa, automaticamente, compor o espaço científico, ainda mais excludente em relação às ideologias contra-hegemônicas.

As mulheres com deficiência têm esse duplo obstáculo da exclusão a transpor para alcançar o campo científico. É nesse sentido que reflexões acerca da temática, como a proposta por esta investigação, são necessárias para que novos regimes de verdade sejam experimentados pelos sujeitos sociais. Por essa razão, ao longo dos anos, principalmente com as teorias feministas, a discussão sobre a participação desigual das mulheres, os estereótipos de gênero e a luta para contribuir e estimular seu protagonismo tem sido constante e revitalizada. Apesar das grandes dificuldades, as mulheres têm ocupado, cada vez mais, outros espaços até então destinados aos homens e, na educação superior, essa realidade não é diferente.

\section{Procedimentos metodológicos}

Para o desenvolvimento desta investigação científica optou-se por uma abordagem quantitativa, fundamentada nos microdados do INEP, de 2010 e de 2018, em relação à docência do ensino superior brasileiro, bem como em dados gerais do IBGE. O ano de 2010 foi selecionado por marcar o último censo 
realizado pelo IBGE, no qual se tem como estatística, entre outros dados, o percentual de pessoas com deficiência que compõem a sociedade brasileira. Já a escolha de 2018 refere-se aos últimos microdados disponibilizados pelo INEP em relação à docência do ensino superior.

Com base nos dados do IBGE, foi possível extrair o percentual de pessoas com deficiência no Brasil, bem como mensurar, desse total, o quantitativo de homens e de mulheres. Conhecendo essas informações, elencouse categorias de busca na base de dados do INEP, com o intuito de extrair as seguintes informações: mulheres e homens docentes do ensino superior, docentes do ensino superior com e sem deficiência, mulheres e homens com deficiência docentes do ensino superior, formação das mulheres com deficiência docentes do ensino superior e formação dos homens com deficiência docentes do ensino superior.

O percurso traçado por este estudo parte de uma coleta de dados mais geral até adentrar naqueles mais específicos. Com essa estratégia, é possível compreender, a partir desse recorte, que ser mulher e com deficiência são dois marcadores de silenciamento e de exclusão presentes, também, na docência do ensino superior brasileiro. Para tanto, os dados extraídos do INEP receberam um tratamento analítico por meio do editor de planilhas Microsoft Excel, sendo convertidos em Gráficos, que apresentam os totais de pessoas em cada uma das categorias elencadas, bem como em Tabelas, que contêm os percentuais representativos desses quantitativos, de modo a clarificar a visualização dos dados.

No tocante aos objetivos, esta pesquisa se caracteriza como exploratória, com o intuito de alcançar um maior conhecimento acerca da temática proposta. Para Gil (2002, p. 41), a pesquisa exploratória busca “[...] proporcionar maior familiaridade com o problema, com vistas a torná-lo mais explícito ou a constituir hipóteses. Pode-se dizer que essas pesquisas têm como objetivo principal o aprimoramento de ideias ou a descoberta de intuições". Coadunando com essa perspectiva, Triviños (1987, p. 109) aponta que "os estudos 
exploratórios permitem ao investigador aumentar sua experiência em torno de determinado problema".

\section{Resultados da pesquisa}

No Brasil, ainda que o percentual de mulheres seja maior que o de homens, como demonstram os dados do IBGE Educa (2018), segundo o qual o país conta com $51,7 \%$ de mulheres e $48,3 \%$ de homens, no âmbito da docência do ensino superior, o quantitativo de homens é maior que o de mulheres. Ao analisar os microdados do INEP de 2010, as mulheres constituem um total de 165.208 docentes do ensino superior, o que equivale a $45 \%$ do total de docentes, enquanto os homens eram 201.674, o que corresponde a 55\%. Já no ano de 2018, as mulheres docentes do ensino superior somam $184.079(46 \%)$ e os homens 213.814(54\%) do total de professores.

Apesar do quantitativo de mulheres nessa categoria se mostrar menor que o número de homens, há um indicativo de progressão no transcorrer dos 8 anos, conforme demonstra o gráfico 1. Com o aumento de 18.871 docentes mulheres no período analisado, o percentual de participação feminina sai de $45 \%$, em 2010, para 46\%, em 2018, com média de crescimento, de cerca de 2.359 novas mulheres docentes do ensino superior por ano. Já em relação aos homens, observa-se que, nesse mesmo período, houve crescimento de 12.140, ou aproximadamente 1.517 ao ano. Em termos de proporcionalidade, verifica-se a diminuição de 1 ponto percentual da representatividade dos homens no ensino superior de 2010 a 2018. Mesmo assim, as mulheres ainda estão em desvantagem numérica em relação aos homens. Um ponto positivo é que a média de mulheres ingressantes cresceu $1 \%$ ao longo dos anos analisados.

Tal fato possibilita inferir que as mulheres estão ocupando mais o campo científico, mesmo com os desafios que enfrentam cotidianamente e com o processo sócio-histórico de exclusão arraigado nos movimentos hegemônicos. De todo modo, a ampliação da participação das mulheres na docência do ensino superior ainda é um desafio a ser concretizado paulatinamente. 
Gráfico 1 - Mulheres e homens docentes do ensino superior 2010/2018

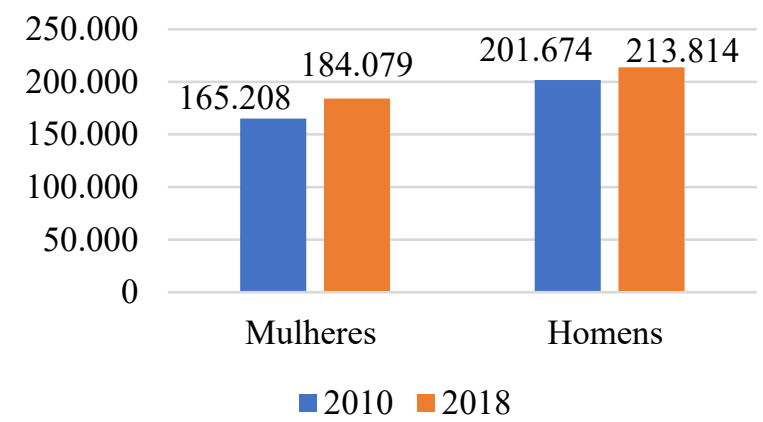

\begin{tabular}{ccc} 
& $\mathbf{2 0 1 0}$ & $\mathbf{2 0 1 8}$ \\
\hline Mulheres & $45 \%$ & $46 \%$ \\
Homens & $55 \%$ & $54 \%$
\end{tabular}

Fonte: Elaborado pelas autoras com base nos dados do INEP 2010/2018.

Ao verificar os dados do INEP em relação à quantidade de docentes do ensino superior com e sem deficiência, observa-se que, em 2010, o percentual de docentes com deficiência, nessa modalidade, representa 1\%. Em 2018, os docentes com deficiência, mesmo aumentando em números absolutos, conforme apresenta o gráfico 2 , ainda representam estatisticamente $1 \%$, tendo em vista a ampliação do total de docentes do ensino superior, enquanto os sem deficiência somam $89 \%$ e os $10 \%$ restantes se referem a informações não disponíveis.

Nota-se, com isso, que, ao se agregar à categoria sexo um outro estigma periférico, o da deficiência, a exclusão se aprofunda, tornando inexpressivo o quantitativo de pessoas com deficiência na docência do ensino superior brasileiro, tanto em 2010 quanto em 2018. Nesse sentido, observa-se: a despeito da existência de leis como a 8.213/1991 (na qual as instituições, dependendo do porte, precisam contar com o percentual de $2 \%$ a $5 \%$ de pessoas com deficiência em seu quadro funcional) e a 8.112/1990 (que estabelece o quantitativo de até $20 \%$ das vagas dos concursos públicos para esses sujeitos), a participação efetiva das pessoas com deficiência na docência do ensino superior do país está aquém do estabelecido. 
Gráfico 2 - Docentes do ensino superior com e sem deficiência 2010/2018

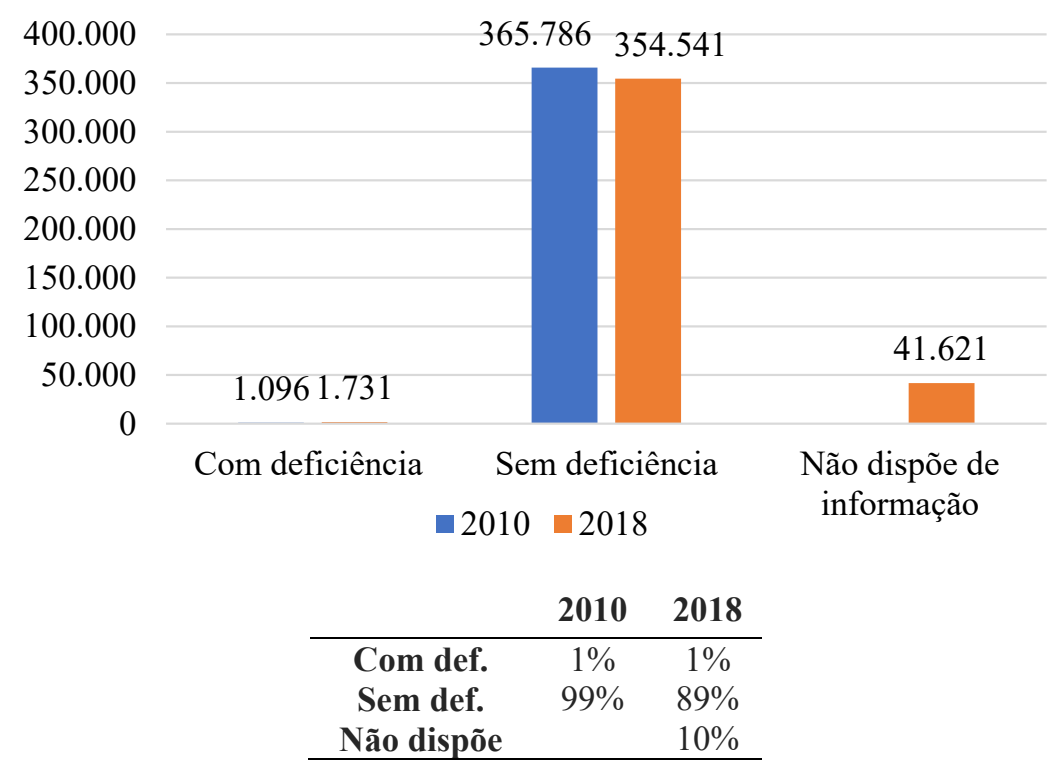

Fonte: Elaborado pelas autoras com base nos dados do INEP 2010/2018.

Como já mencionado, $23,9 \%$ da população brasileira conta com algum tipo de deficiência, como apontam os dados da Cartilha do Censo 2010 Pessoas com Deficiência, da SDH/PR (2012). Nesse percentual, há um predomínio de mulheres. A partir dessa afirmação, resgatam-se duas indagações que complementam a questão-problema norteadora desta investigação científica. Há um número maior de mulheres com deficiência na docência do ensino superior brasileiro que o de homens? Entre as mulheres essa invisibilidade se agrava?

Os microdados do INEP, apresentados no gráfico 3, demonstram que, em 2010, as mulheres com deficiência docentes do ensino superior representavam $36 \%$, enquanto os homens correspondiam a 64\%. Em 2018, os números indicam $40 \%$ de mulheres nessa modalidade e $60 \%$ de homens. Entre as mulheres, verifica-se que houve um aumento de $4 \%$ ao longo dos 8 anos destacados. Já o percentual de homens diminuiu $4 \%$ no período.

No comparativo entre o percentual de mulheres e o de homens com deficiência em ambos os momentos analisados, o número de homens supera o de mulheres, ainda que o quantitativo de mulheres com deficiência no país seja 
maior que o de homens, segundo dados da Cartilha do Censo 2010 - Pessoas com Deficiência, da SDH/PR (2012). No entanto, salienta-se que, conforme as estatísticas aqui apresentadas, embora o percentual de homens ainda seja mais expressivo, o aumento do número de pessoas com deficiência na docência brasileira, nesse intervalo de tempo, é representativo para as mulheres.

De todo modo, esses dados possibilitam notar que, de fato, a ciência prestigia um grupo hegemônico em detrimento da diversidade. Ao se agregar ao estigma da feminilidade o da deficiência, percebe-se que os homens com deficiência e de um modo ainda mais profundo as mulheres com deficiência, de fato, têm muita dificuldade em seguir a carreira docente do ensino superior, assim como ocorre também com outros grupos que não correspondem aos padrões estabelecidos, pois a ciência é masculina, androcêntrica, ocidental, elitizada, branca e perfectiva.

A masculinidade da ciência, que se expressa por meio da objetividade, afasta do ambiente da docência do ensino superior pessoas dos grupos contrahegemônicos, como as mulheres com deficiência. Nessa perspectiva, para se incluir as agremiações historicamente apartadas da docência do ensino superior, faz-se necessária uma remodelação da própria concepção científica e não apenas medidas paliativas de integração dos grupos subalternizados à lógica dominante.

Gráfico 3 - Mulheres e homens com deficiência docentes do ensino superior 2010/2018

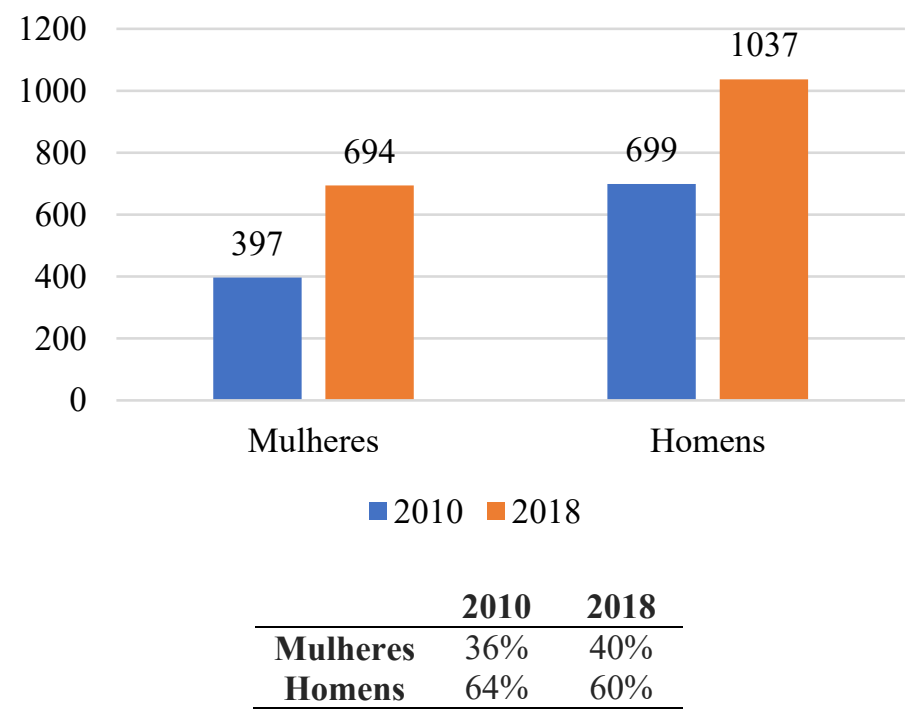

Fonte: Elaborado pelas autoras com base nos dados do INEP 2010/2018. 
Outro aspecto importante a ser observado é a formação desses docentes. Como já discutido anteriormente, a visão reducionista que as pessoas com deficiência enfrentam acerca de sua condição as afasta de determinadas atividades e compromete, muitas vezes, a construção do processo de aprendizagem e a permanência no ensino superior. Em 2010, como já mencionado no gráfico anterior, somam-se 397 mulheres na docência do ensino superior brasileira. Desse quantitativo, conforme os dados apresentados no gráfico 4, 28\% são doutoras, 40\% mestres, 26\% especialistas, 5\% graduadas e 1\% não graduada ${ }^{4}$. Já em 2018, entre as 694 mulheres com deficiência docentes do ensino superior, verifica-se que 35\% são doutoras, 38\% são mestres, $26 \%$ são especialistas e $1 \%$ é graduada.

Ao comparar os dados de 2010 com os de 2018, observa-se que a formação de mulheres doutoras teve um aumento de 7\% e houve uma queda de $2 \%$ das mulheres mestres. É notório, em termos quantitativos, ao analisar o referido gráfico, que o total de ambas as formações aumentou, no entanto, faz-se necessário considerar que o quantitativo geral de mulheres com deficiência docentes do ensino superior também cresceu e, por isso, há essas variações percentuais. A proporção de especialistas permaneceu inalterada no intervalo de tempo analisado, no quantitativo de $26 \%$, a de graduadas reduziu de $5 \%$ para $1 \%$ e a categoria sem graduação deixou de compor os quadros de formação em 2018. Nota-se, com isso, uma melhoria na formação dessas profissionais no transcorrer do período em análise.

Gráfico 4 - Formação das mulheres com deficiência docentes do ensino superior 2010/2018

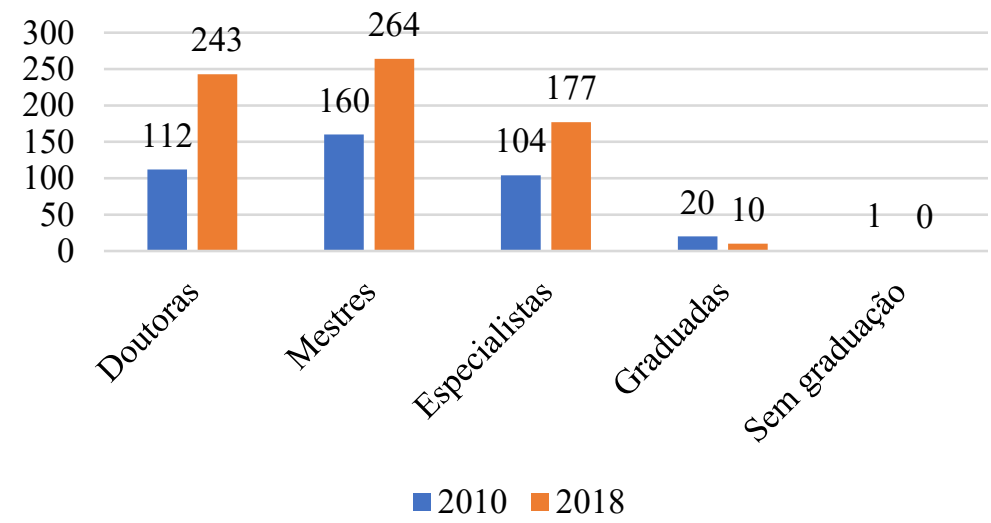




\begin{tabular}{ccc} 
& $\mathbf{2 0 1 0}$ & $\mathbf{2 0 1 8}$ \\
\hline Doutoras & $28 \%$ & $35 \%$ \\
Mestres & $40 \%$ & $38 \%$ \\
Especialistas & $26 \%$ & $26 \%$ \\
Graduadas & $5 \%$ & $1 \%$ \\
Sem graduação & $1 \%$ & $0 \%$ \\
\hline
\end{tabular}

Fonte: Elaborado pelas autoras com base nos dados do INEP 2010/2018.

Em relação à formação dos homens com deficiência docentes do ensino superior 2010/2018, apresentada no gráfico 5, verifica-se que os doutores, em 2010, representam 26\% e em 2018 esse número aumentou 8\%, completando $34 \%$. Para os mestres, apesar de o gráfico indicar aumento, em termos percentuais, o número se manteve em $38 \%$, tendo em vista que o quantitativo geral de homens também se ampliou nesse período. No tocante aos docentes especialistas, o percentual diminuiu em $3 \%$, de $29 \%$ para $26 \%$, entre os graduados a proporção partiu de $6 \%$ para $2 \%$ e a categoria de não graduados deixou de existir em 2018. Assim como ocorreu no caso das mulheres com deficiência, observa-se que houve melhoria na formação desses profissionais no intervalo em análise.

Gráfico 5 - Formação dos homens com deficiência docentes do ensino superior 2010/2018

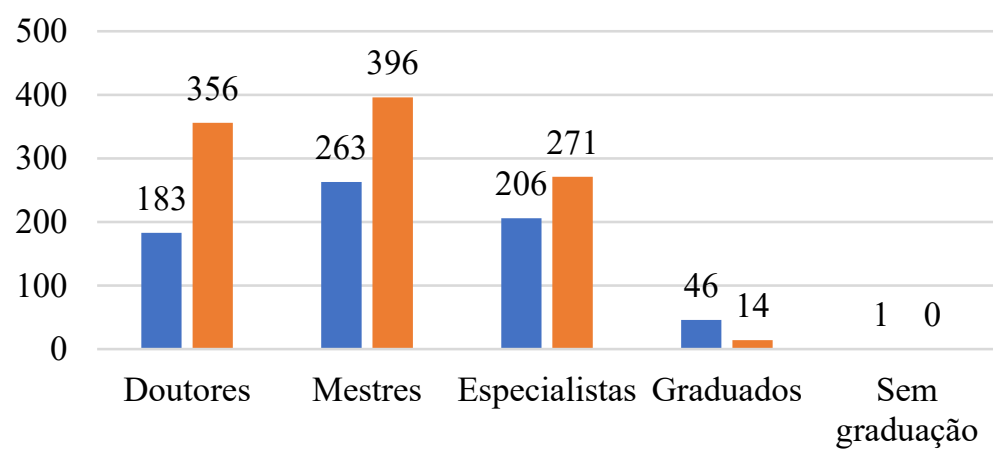

$\square 2010 \square 2018$

\begin{tabular}{ccc} 
& $\mathbf{2 0 1 0}$ & $\mathbf{2 0 1 8}$ \\
\hline Doutores & $26 \%$ & $34 \%$ \\
Mestres & $38 \%$ & $38 \%$ \\
Especialistas & $29 \%$ & $26 \%$ \\
Graduados & $6 \%$ & $2 \%$ \\
Sem graduação & $1 \%$ & $0 \%$ \\
\hline
\end{tabular}

Fonte: Elaborado pelas autoras com base nos dados do INEP 2010/2018. 


\section{Considerações finais}

Este artigo representa uma primeira aproximação no tensionamento da questão de gênero $^{5}$ na ciência. Mais especificamente, procurou-se discutir qual a representatividade da mulher com deficiência na docência do ensino superior no Brasil que, além das barreiras de acesso aos direitos sociais, também sofre com as dificuldades de empregabilidade. Apesar da existência de diversos instrumentos legislativos, ingressar no mercado de trabalho não é tarefa fácil.

Existe um estigma de que as pessoas com deficiência são incapazes de exercer sua cidadania, ou seja, esses sujeitos são vistos como inválidos e dependentes, precisando ser amparados por terceiros. Essa concepção contribui significativamente para a dificuldade de inclusão não só no mercado de trabalho, mas nas diversas esferas sociais. Pode-se dizer que os desafios são duplos: primeiro por essas pessoas não serem reconhecidas socialmente como sujeitos produtivos; segundo, pela dificuldade de garantirem sua autonomia econômica e social, o que resulta em exclusão e isolamento.

Conforme os dados do INEP de 2010 e 2018, observa-se que os professores com deficiência no ensino superior representam $1 \%$, um percentual muito baixo se comparado ao total de docentes sem deficiência. Desse 1\%, a quantidade de homens ainda é maior, mas o crescimento é representativo para as mulheres ao longo dos anos. Quanto à formação, verifica-se um incremento no número de doutoras. É importante ressaltar que este artigo é uma tentativa inicial de dar luz à temática. Espera-se, em um estudo futuro, correlacionar as diferenças raciais e de idade e os diversos tipos de deficiência.

Haja vista tantos silenciamentos e exclusões, tensionamentos são necessários para dar voz às mulheres invisibilizadas e lançar luz em existências negadas e inferiorizadas. Nesse caminho, a ser trilhado cotidianamente a partir de estudos como o desenvolvido nesta investigação científica, salienta-se que a comunicação, como elemento capaz de dirimir as barreiras do silenciamento e da exclusão, destaca-se na constituição de uma nova cultura social, esta pautada na inclusão de grupos subalternizados, como as mulheres com deficiência. 
Financiamento

Coordenação de Aperfeiçoamento de Pessoal de Nível Superior (Capes)

\section{Referências}

BANDEIRA, Lourdes. A contribuição da crítica feminista à ciência. Revista Estudos Feministas, Florianópolis, v. 16, n. 1, p. 207-228, 2008.

BARBOZA, Heloisa Helena; ALMEIDA JUNIOR, Vitor de Azevedo. Reconhecimento e inclusão das pessoas com deficiência. Revista Brasileira de Direito Civil - RBDCivil, Belo Horizonte, v. 13, p. 17-37, jul./set. 2017.

BRASIL. [Constituição (1988)]. Constituição da República Federativa do Brasil, de 5 de outubro de 1988. Diário Oficial [da] República Federativa do Brasil, Brasília, DF, 5. out. 1988.

BRASIL. Decreto n. 186, de 9 de julho de 2008. Aprova o texto da Convenção sobre os Direitos das Pessoas com Deficiência e de seu Protocolo Facultativo, assinados em Nova Iorque, em 30 de março de 2007. Diário Oficial [da] República Federativa do Brasil, Brasília, DF, ano 145, n. 131, p. 1, 10 jul. 2008.

BRASIL. Lei n. 8.112, de 11 de dezembro de 1990. Dispõe sobre o regime jurídico dos servidores públicos civis da União, das autarquias e das fundações públicas federais. Diário Oficial [da] República Federativa do Brasil, Brasília, DF, ano 127, 11 dez. 1990.

BRASIL. Lei n. 8.213, de 24 de julho de 1991. Dispõe sobre os Planos de Benefícios da Previdência Social e dá outras providências. Diário Oficial [da] República Federativa do Brasil, Brasília, DF, ano 128, 24 jul. 1991.

BRASIL. Lei n. 13.146, de 6 de julho de 2015. Institui a Lei Brasileira da Pessoa com Deficiência (Estatuto da Pessoa com Deficiência). Diário Oficial [da] República Federativa do Brasil, Brasília, DF, ano 152, n. 127, p. 2, 7 jul. 2015.

BUTLER, Judith. Problemas de gênero: feminismo e subversão da identidade. Tradução Renato Aguiar. Rio de Janeiro: Civilização Brasileira, 2003.

DINIZ, Débora. O que é deficiência. São Paulo: Brasiliense, 2007.

FARIAS, Adenize Queiroz de. Gênero e deficiência: uma história feminina de ruptura e superação de vulnerabilidades. Orientador: Windyz Brazão Ferreira. 2011. Dissertação (Mestrado em Educação) - Programa de Pós-Graduação em Educação, Universidade Federal da Paraíba, João Pessoa, 2011. 
FARIAS, Adenize Queiroz de. Trajetórias educacionais de mulheres: uma leitura interseccional da deficiência. Orientador: Maria Eulina Pessoa de Carvalho. 2017. Tese (Doutorado em Educação) - Programa de Pós-Graduação em Educação, Universidade Federal da Paraíba, João Pessoa, 2017.

GIL, Antônio Carlos. Como elaborar projetos de pesquisa. 4. ed. São Paulo: Atlas, 2002.

GOMES, Ruthie Bonan et al. Novos diálogos dos estudos feministas da deficiência. Revista Estudos Feministas, Florianópolis, v. 27, n. 1, 2019.

IBGE EDUCA - Instituto Brasileiro de Geografia e Estatística. Quantidade de homens e mulheres. Brasília, DF, 2018.

INEP - Instituto Nacional de Estudos e Pesquisas Educacionais Anísio Teixeira. Microdados. 2010/2018. Disponível em http://portal.inep.gov.br/microdados. Acesso em: 12 set. 2020.

MANTOAN, Maria Teresa Eglér. Inclusão, diferença e deficiência: sentidos, deslocamentos, proposições. Revista Inclusão Social, Brasília, DF, v. 10 n. 2, p. 37-46, jan./jun. 2017.

MELLO, Anahi Guedes de; NUERNBERG, Adriano Henrique. Gênero e deficiência: interseções e perspectivas. Estudos Feministas, Florianópolis, n. 20, v. 3, p. 635-655, set./dez. 2012.

MINISTÉRIO DA ECONOMIA. Contratações de pessoas com deficiência batem recorde em 2018, 2018. Disponível em: https://www.gov.br/ptbr/noticias/trabalho-e-previdencia/2019/02/contratacoes-de-pessoas-comdeficiencia-batem-recorde-em-2018. Acesso em: 12 set. 2020.

PIOVESAN, Flávia. Direitos humanos e o direito constitucional internacional. 14. ed. rev. atual. São Paulo: Saraiva, 2013.

RAGO, Margareth. Descobrindo historicamente o gênero. Cadernos Pagu, Campinas, n. 11, p. 89-98, 1998.

SASSAKI, Romeu Kazumi. Inclusão: construindo uma sociedade para todos. 8. ed. Rio de Janeiro: WVA, 2010.

SECRETARIA DE DIREITOS HUMANOS DA PRESIDÊNCIA DA REPÚBLICA. Cartilha do Censo 2010: pessoas com deficiência. Brasília, DF: SDH-PR/SNPD, 2012. 
SILVA, Elizabete Rodrigues da. A (in)visibilidade das mulheres no campo científico. Revista HISTEDBR On-line, Campinas, n. 30, p.133-148, jun. 2008 .

SILVA, Fabiane Ferreira da; RIBEIRO, Paula Regina Costa. Trajetórias de mulheres na ciência: "ser cientista" e "ser mulher". Ciência \& Educação, Bauru, v. 20, n. 2, p. 449-466, 2014

TRIVIÑOS, Augusto Nibaldo Silva. Introdução à pesquisa em ciências sociais: a pesquisa qualitativa em educação. São Paulo: Atlas, 1987.

\title{
Women with disabilities in Brazilian teaching
}

\begin{abstract}
The aim of this research is to discuss the representativeness of women with disabilities in Brazilian higher education teaching. It is understood that the research subjects have two markers of silence and exclusion: being a woman and with disabilities. Regarding the methodological aspects, the research is classified as quantitative. It was based on the secondary analysis of data from the National Institute for Educational Studies and Research Anísio Teixeira, from 2010 and 2018, as well as from the general data from the Brazilian Institute of Geography and Statistics. With this investigation, it was observed that teachers with disabilities represent only $1 \%$ of those who make up Brazilian higher education, women being a minority compared to the number of men, although the graphs show a quantitative increase in female representation over the years.
\end{abstract}

Keywords: Science and Gender; University Education; Exclusion; Science and Minority.

Recebido: $15 / 10 / 2020$

Aceito: 02/06/2021

\section{Declaração de autoria}

Concepção e elaboração do estudo: Daniela Priscila de Oliveira Veronezi, Geisa Müller de Campos Ribeiro, Suely Henrique de Aquino Gomes.

Coleta de dados: Daniela Priscila de Oliveira Veronezi, Geisa Müller de Campos Ribeiro.

Análise e interpretação de dados: Daniela Priscila de Oliveira Veronezi, Geisa Müller de Campos Ribeiro.

Redação: Daniela Priscila de Oliveira Veronezi, Geisa Müller de Campos Ribeiro. 
Revisão crítica do manuscrito: Daniela Priscila de Oliveira Veronezi, Geisa Müller de Campos Ribeiro, Suely Henrique de Aquino Gomes.

\section{Como citar:}

VERONEZI, Daniela Priscila de Oliveira; RIBEIRO, Geisa Müller de Campos; GOMES, Suely Henrique de Aquino. Mulheres com deficiência na docência brasileira. Em Questão, Porto Alegre, v. 28, n. 2, e-108417, abr./jun. 2022. https://doi.org/10.19132/1808-5245282.108417

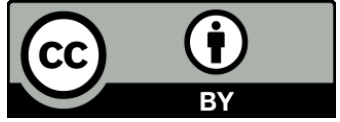

${ }^{1}$ As palavras-chave utilizadas para a busca foram: professores com deficiência; docentes com deficiência; mulher com deficiência; pesquisa; entre outras.

2 SASSAKI, Romeu Kazumi. Inclusão da pessoa com deficiência no mercado de trabalho. São Paulo: Prodef, 1997.

3 Ministério da Economia. Contratação de pessoas com deficiência bate recorde após fiscalização do Trabalho. [S.1.], 2019.

4 Cabe reforçar que os dados do INEP englobam as instituições públicas federais, privadas com fins lucrativos, privadas sem fins lucrativos e públicas estaduais. Em muitas faculdades privadas existem professores somente com graduação.

5 Apesar da adoção, nesta investigação, da categoria "mulher" afirmada como termo operacional para estender visibilidade e legitimidade como sujeitos políticos, acredita-se que essa variável (sexo) é um dos marcadores sociais de exclusão e de desigualdade, balizando, inclusive, as categorias de gênero. 